\title{
Exploring the powerful phytoarsenal of white grape marc against bacteria and parasites causing significant diseases
}

\author{
José-Luis Rodríguez Rama ${ }^{1} \cdot$ Natalia Mallo $^{2} \cdot$ Marco Biddau $^{2} \cdot$ Francisco Fernandes $^{3} \cdot$ Trinidad de Miguel $^{1}$ (D) \\ Lilach Sheiner $^{2} \cdot$ Altino Choupina $^{3} \cdot$ Marta Lores $^{4}$
}

Received: 29 October 2019 / Accepted: 19 December 2019

(C) Springer-Verlag GmbH Germany, part of Springer Nature 2020

\begin{abstract}
Natural extracts containing high polyphenolic concentration possess antibacterial, anti-parasitic and fungicidal activities. The present research characterises two extracts based on white grape marc, a winemaking by-product, describing their physicochemical features and antimicrobial capacities. The main components of these extracts are phenolic acids, flavan-3-ols and their gallates and flavonols and their glycosides. As a result of this complex composition, the extracts showed pronounced bioactivities with potential uses in agricultural, pharmaceutical and cosmetic industries. Polyphenol compounds were extracted by using hydro-organic solvent mixtures from the by-product of Albariño white wines (Galicia, NW Spain) production. The in vitro antimicrobial activity of these extracts was evaluated on Grampositive and Gram-negative bacteria and Apicomplexan and Oomycota parasites. Microbial species investigated are causing agents of several human and animal diseases, such as foodborne illnesses (Bacillus cereus, Escherichia coli, Salmonella enterica, and Toxoplasma gondii), skin infections and/or mastitis (Staphylococcus aureus and Streptococcus uberis), malaria (Plasmodium falciparum) and plant infections as "chestnut ink" or "root rot" (Phytophthora cinnamomi). Both extracts showed activity against all the tested species, being nontoxic for the host. So, they could be used for the development of biocides to control a wide range of pathogenic agents and contribute to the enhancement of winemaking industry by-products.
\end{abstract}

Keywords Antibacterial $\cdot$ Anti-parasitic $\cdot$ Enhancement of winemaking by-products $\cdot$ Grape marc $\cdot$ Natural extract $\cdot$ Polyphenols

José Luis Rodríguez Rama and Natalia Mallo contributed equally to this work.

Responsible editor: Giovanni Benelli

Trinidad de Miguel

trinidad.demiguel@usc.es

1 Department of Microbiology and Parasitology, University of Santiago de Compostela, Santiago de Compostela, E-15782 A Coruña, Spain

2 Wellcome Centre for Integrative Parasitology. Department of Infection, Immunity and Inflamation., University of Glasgow, 120 University Place, Glasgow, UK

3 Department of Socioeconomical systems, I. Politécnico Bragança, 5300-253 Terras Trás-os-Montes, Portugal

4 Department of Analytical Chemistry, Nutrition and Food Science, Laboratory of Research and Development of Analytical Solutions (LIDSA), University of Santiago de Compostela, Santiago de Compostela, E-15782 A Coruña, Spain

\section{Introduction}

Grapes are one of the largest fruit crops in the world. According to the Food and Agricultural Organization (FAO) of the United Nations, $>67$ million tons of grapes are produced annually worldwide, and during the production of wines, there is a big amount of the grapes that end up as byproducts. Among the mentioned by-products, grape marc (peel, seeds and stems after wine production) constitutes a very non-expensive material with numerous interesting activities due to its composition. That composition, in general, depends on the variety of the grape, type of soil, climate and wine making techniques (Friedman 2014).

Grape marc also contains several bioactive compounds which are different to those found in grapes and wine, opening a new path for exploring its potential anti-pathogenic activity. Activity of wine by-products against pathogenic bacteria, virus, fungi toxins and parasites has been proved (Friedman 2014). This fact, together with the interest risen in the last 
decades, about finding natural bioactive compounds against different diseases due to antimicrobial resistance among other issues, makes grape marc a good candidate to find new effective treatments and therapeutic strategies. Its composition is very rich and complex. Some of the compounds included are antioxidant phenolic compounds, which have been described as potential agents against several pathogenic diseases. Such phenolic compounds are not well extracted into the wine during winemaking process, remaining in the grape marc, being thus this by-product very rich in polyphenols (Beres et al. 2017; Friedman 2014).

An antioxidant agent is a molecule that delays, prevents or clears oxidative damage in a target cell (Gutteridge and Halliwell 2010). They can act in biological systems by different mechanisms, including electron donation (acting as reducing agents), metallic ion chelation (deleting potential free radicals), or by regulation of genic expression (Gutteridge and Halliwell 2010). This group of substances act at low concentrations and significantly inhibit or retard the oxidative process while they are oxidized. Some examples of antioxidants are ascorbic acid, uric acid and some polyphenols as resveratrol (Zampelas and Micha 2015). Their employment as additives is broadly distributed in industry field to delay, prevent or eliminate damage caused by oxidation. Recently, some plant extracts have been reported to have good antioxidant and antimicrobial properties due to their polyphenolic and protein compounds (Piscopo et al. 2019; Tortora et al. 2019; Benabderrahmane et al. 2018; Benabderrahmane et al. 2019). Due to its complex composition, containing antioxidant dietary fibre, as well as extractable and non-extractable polyphenol content, grape marc extracts have a great potential to display extensive uses in agricultural, pharmaceutical and cosmetic industries among others (Bargiacchi et al. 2017; Placha et al. 2013; de O Ribeiro et al. 2018; Tayengwa and Mapiye 2018). The grape marc contains the following antioxidative polyphenolic categories: phenolic acids, flavonoids, lignans and stilbenes (Sagdic et al. 2011a). The healthpromoting and disease-preventing benefits of different types of grape polyphenols are well documented (Simões et al. 2009; Yadav et al. 2015). Phenolic acids, flavan-3-ols and their gallates and flavonols and their glycosides are the main phenolic constituents of white grape marc (Álvarez-Casas et al. 2014).

Natural extracts as the ones studied in the present work have raised interest in the last years as an alternative to general antibiotics and anti-parasitic treatments (Murphy et al. 2017). Extensive use of antimicrobial drugs has generated an increase in antimicrobial resistances being a worrying issue in the present moment. The use of natural extracts with antimicrobial capacity can be a good alternative that could avoid the generation of resistances
(Murphy et al. 2017; European Centre for Disease Prevention and Control (ECDC) et al. 2017). On this way, the microbial species studied in the present work are involved in several diseases in humans and animals, such as foodborne illnesses (Bacillus cereus, Escherichia coli, Salmonella enterica subsp. enterica), skin infections (Staphylococcus aureus) and mastitis (Streptococcus uberis).

Besides, human and animal parasite infections such as Malaria (Plasmodium falciparum) or Toxoplasmosis (Toxoplasma gondii) have been considered. Plasmodium species causes complex diseases and constitutes a serious health problem around the world. The World Health Organization estimated a number of 219 million people infected by Plasmodium which was distributed in 87 countries, resulting to almost 500,000 deaths and a considerably large population at risk of infection by this parasite in 2017 (World Health Organization, Malaria 2019). T. gondii is a protozoan parasite belonging to the phyla Apicomplexa. It is the causing agent of toxoplasmosis, a zoonotic disease of worldwide distribution, which generates a significant problem on public health and on global economy. It is considered a high-risk zoonotic agent by the European Food Safety Authority (EFSA) (2019) with an estimated one third of the world's population infected (Seeber and Steinfelder 2016).

Last, to evaluate the potential of the Albariño extracts in plant infections, we chose Phytophthora cinnamomi an oomycete species that causes known plant diseases as "chestnut ink" in chestnuts (Castanea sativa Miller) causing a considerable decline of this culture in Europe. P. cinnamomi is a soil pathogen that has a wide range of hosts in several countries and different climates. Since oomycetes have other pathogenicity mechanisms than fungi, they are not easily controlled by usual fungicides and often develop resistance against the rare anti-oomycete products available (Davison 2002; Judelson and Blanco 2005).

Due to climate change and migration (Yan et al. 2016), among other factors, a large proportion of the population is at risk of infection with parasites and other infectious agents, being, thus, the study of infectious diseases an emerging field (Tauxe et al. 2010). Trying to find new treatments to these diseases becomes a relevant topic of study nowadays mainly due to the lack of effectiveness or appearance of side effects with the existing ones, emergence of drug-resistance or just nonexistence of treatment.

The present work describes the polyphenolic profile and antimicrobial capacities of bioactive extracts obtained from the white winemaking by-products to give them a new use and valorisation. Bioactive polyphenols were extracted with hydro-organic solvent mixtures from the by-product of the production of high-quality Albariño white wines (Galicia, NW Spain). We then evaluated the in vitro antimicrobial activity of two extracts from Albariño grape marc using two 
different hydro-organic mixtures $\left(\mathrm{HO}_{\mathrm{L}} \& \mathrm{HO}_{\mathrm{P}}\right)$. Extracts were used against relevant microorganisms, including Grampositive and Gram-negative bacteria, two Apicomplexan parasite species and one Oomycota parasite.

\section{Material and methods}

\section{Extracts production and polyphenolic evaluation}

The extraction procedure is a green and straightforward process with few steps, under gentle conditions and using noncontaminating materials, while preventing the obtained eluates from containing suspended solids. Raw material is white grape marc from Vitis vinifera var. Albariño. Extract and process are patent-protected (Lores et al. 2014a, Lores et al. 2014 b) and can be obtained on lab, pilot or industrial scales.

Two different extracts have been produced using this process, whose main difference is the nature of the organic solvent (abbreviated as $\mathrm{L}$ and $\mathrm{P}$ for protection of patent exploitation rights) in the hydro-organic mixtures used for eluting the target bioactive compounds from the grape marc. Both solvents are miscible with both hydrophilic and hydrophobic compounds and therefore ideal for extracting plant phenolics as they comprise a wide range of polarities. Nevertheless, they selectively solubilise different polyphenolic compounds, as will be shown later in the qualitative profiles; but they also have different degrees of solubilising capacity for the same phenolics, which will be reflected in the concentration of the polyphenols common to both extracts. In addition, both solvents are GRAS (generally recognized as safe) and environmentally friendly, which is very important when preparing formulations for their potential applications.

\section{Anti-bacterial assays}

$20 \mu \mathrm{L}$ of a cellular suspension of the microorganism to test in late logarithmic phase was incubated in phosphate-buffered saline (PBS) with different extract concentrations (20, 10, 5, $2.5,1.25,0.625$ and $0 \%$ ). The assay was performed in a sterile 96 multiwell plate, with $200 \mu \mathrm{l}$ of final volume and incubated at $37{ }^{\circ} \mathrm{C}$ for $1,5-3 \mathrm{~h}$ depending on the species. Time was adjusted to $3 \mathrm{~h}$ for $E$. coli ATCC 8739 and $S$. enterica subsp. enterica CECT 554, to $2 \mathrm{~h}$ for $B$. cereus CECT193 and to 1,5 h for S. uberis CECT 994 and S. aureus CECT 59. The incubation time was adjusted according to the survival of the positive control (optimal survival 50-200 colony forming units (CFU) from a $10^{-6}$ dilution). Some strains are more sensitive, and their survival is affected under the test conditions. To estimate the survival after incubation, samples of $20 \mu \mathrm{l}$ with different concentrations from a serial dilution were grown on agar plates. After $16 \mathrm{~h}$ of incubation at $37^{\circ} \mathrm{C}$, the CFUs were counted and used to calculate $\mathrm{IC}_{50}$ values, with

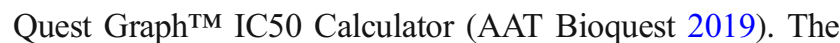
culture media used were Heart Brain Infusion (HBI) for S. uberis and Luria-Bertani (LB) for the rest of the species tested. All experiments were performed in triplicate.

\section{Anti-parasitic assays}

Growth inhibition of three species was evaluated: one plant parasite, P. cinnamomi CECT 20919, and two human and animal parasites, $P$. falciparum 3D7 and T. gondii RH Type 1.

\section{P. cinnamomi}

The inhibition's percentage in the growth of $P$. cinnamomi was determined in both extracts, at the concentrations of $0 \%, 4 \%$ and $10 \%$. P. cinnamomi was grown on plates of $90 \mathrm{~mm}$ in diameter, with $50 \mathrm{~mL}$ of potato-dextrose-agar medium (PDA) per plate with the different extract's concentrations at 10,4 and $0 \%$ for 10 days at $22{ }^{\circ} \mathrm{C}$ in the dark. The antifungal capacity has been determined according to the growth inhibition respect to the untreated cultures ( $0 \%$ concentration). Quest Graph ${ }^{\mathrm{TM}}$ IC50 Calculator (AAT Bioquest 2019) application was used to calculate $\mathrm{IC}_{50 \mathrm{~s}}$.

\section{Toxoplasma gondii}

Human foreskin fibroblasts (HFF) were cultured in black optical bottom 96-well culture plates until confluence was reached. At this point, freshly egressed red-fluorescent T. gondii tachyzoites were washed and resuspended in culture medium (Dulbecco's modified Eagle's medium (DMEM) supplemented with penicillin-streptomycin antibiotics and a $10 \%$ of fetal bovine serum (FBS) without phenol red (Gibco BRL Life Technologies, Rockville, Md.)) ${ }^{1}$. Each well of the HFF culture plate was then infected with approximately 500 parasites. Parasites were treated with the different extracts at concentrations of $2,1,0.5,0.25,0.125,0.065$ and $0 \%(v / \mathrm{v}$ drug/medium) in triplicate and incubated for 7 days at $37{ }^{\circ} \mathrm{C}$ under $5 \% \mathrm{CO}_{2}$ and $100 \%$ humidity conditions. Fluorescence was read daily in a PHERAstar FS plate reader, and data from each drug concentration replicates averaged. Both excitation (540 nm) and emission (590 nm) were read using the bottom optics option in the reader. Each experiment included triplicate controls for the uninfected host cells cultured in medium containing the extracts, as well as triplicate controls of $T$. gondiiinfected host cells cultured in medium containing only the solvents used to resuspend the extracts ${ }^{2}$. Quest Graph ${ }^{\mathrm{TM}}$ IC50 Calculator (AAT Bioquest 2019) application was used to calculate $\mathrm{IC}_{50 \text { s }}$ from day 2 to 7 . 


\section{Plasmodium falciparum}

P. falciparum was cultured in RPMI 1640 containing $11 \mathrm{mM}$ glucose, $0.5 \%(w / v)$ Albumax II, $200 \mu \mathrm{M}$ hypoxanthine and $20 \mu \mathrm{g} / \mathrm{ml}$ gentamycin (PAA) in human red blood cells (RBC) at $5 \%(\mathrm{w} / \mathrm{v})$ haematocrit, as previously described $(2,3)$. Parasite cultures were maintained at $37{ }^{\circ} \mathrm{C}$ under an oxygen reduced atmosphere containing $1 \%(v / v) \mathrm{O}_{2}, 3 \%(\mathrm{v} / \mathrm{v}) \mathrm{CO}_{2}$ and $96 \%$ (v/v) $\mathrm{N}_{2}$ (Taylor 1950). To analyse $\mathrm{IC}_{50}$ concentrations of the extracts, wild-type parasites were cultured in black optical bottom 96 -well plates at $0.3 \%$ parasitemia and $2.5 \%$ haematocrit for $72 \mathrm{~h}$ at $37{ }^{\circ} \mathrm{C}$ in culturing chambers with reduced oxygen. Infected RBC were exposed to 1:2 dilutions of the extracts in triplicates from a concentration of $2 \%$ to $0.004 \%(\mathrm{v} / \mathrm{v})$ including no drug controls. Similar triplicate conditions were also set up for solvent-only controls in each plate. After incubation time, plates were frozen overnight at $-20^{\circ} \mathrm{C}$. The plates were then thawed at RT for 3-4 h, and each well added with an equal volume of a $1 \times$ solution of SYBR green (Smilkstein et al. 2004). After incubation for $1 \mathrm{~h}$ in the dark, fluorescent signal was acquired in a PHERA star FS plate reader using a 485-520 filter. Average values for each triplicate were then used to calculate $\mathrm{IC}_{50}$ concentrations using the software Quest Graph ${ }^{\mathrm{TM}}$ IC50 Calculator (AAT Bioquest 2019).

Cytotoxicity of the compounds to human cells was tested by adding the same dilutions used for the IC50s to the uninfected HFFs confluent monolayers. A control of HFFs growing under standard conditions was included in the same plate and no differences were observed between both cultures. All the treatments were included in triplicates in the same 96 well plate for each of the compounds, and the experiment was repeated 3 times.

\section{Results}

\section{Polyphenol-rich extract composition}

The white grape marc extracts obtained showed a high content in polyphenols as it can be observed in Table 1. Nevertheless, there was a relevant difference in the composition between the two extracts. $\mathrm{HO}_{\mathrm{L}}$ showed higher levels of catechin, epicatechin and isoquercetin than $\mathrm{HO}_{\mathrm{P}}$, while $\mathrm{HO}_{\mathrm{P}}$ presented a considerably higher concentration of phologlucinic acid, miquelianin and rutin; also, it is more concentrated in kaempferol, and it has caftaric acid which is not present in $\mathrm{HO}_{\mathrm{L}}$. Polyphenolic compounds abundance and differences between the extracts can be observed in Fig. 1. Stability studies of both extracts showed that their bioactivities are kept at room temperature for at least 1 year. In addition, the extracts maintain their polyphenolic profile and show thermal stability up to a temperature of $120{ }^{\circ} \mathrm{C}$, which opens up many possibilities for obtaining formulations containing them.

\section{Antibacterial activity}

Both types of bacteria, Gram-negative and Gram-positive, were analysed. The extracts were active against both types. As indicated in Table 2, for most of the bacterial species analysed, the $\mathrm{IC}_{50}$ is lower than $1.25 \%$ with exception of S. uberis which showed a slightly higher value in $\mathrm{HO}_{\mathrm{P}}$. In general, the $\mathrm{HO}_{\mathrm{L}}$ showed a higher activity being its concentration lowest to reduce the growth in 50\%.

\section{Anti-parasitic activity}

Extracts were also tested against the plant parasite $P$. cinnamomi and the human and animal parasite T. gondii and P. falciparum.

On $P$. cinnamomi assay, $\mathrm{HO}_{\mathrm{L}}$ showed a significant higher activity than $\mathrm{HO}_{\mathrm{P}}$ extract as it can be clearly observed in pictures 2 and 3 of Fig. 2. The concentration needed of $\mathrm{HO}_{\mathrm{L}}$ to reach the same activity is six times lower than the quantity necessary for $\mathrm{HO}_{\mathrm{P}}$.

Average values for triplicates were used to calculate $\mathrm{IC}_{50}$ concentrations using Quest Graph ${ }^{\mathrm{TM}}$ IC50 Calculator.

The anti-parasitic activity was assessed by growth inhibition of T. gondii and P. falciparum trophozoites. Both grape marc extracts were able to reduce parasite load as monitored by the $\mathrm{IC}_{50}$ values obtained by fluorimetry, in the case of both Apicomplexan parasite species. Neither extract nor vehicle treatments were toxic to fibroblast cell cultures as it was observed in the controls included. Although both extracts showed activity, $\mathrm{HO}_{\mathrm{L}}$ showed a more efficient rate of antiparasitic activity as the $\mathrm{IC}_{50}$ values obtained were lower than the ones for $\mathrm{HO}_{\mathrm{P}}$.

Regarding T. gondii and P. falciparum, the opposite effect could be observed, being in this case more active $\mathrm{HO}_{\mathrm{P}}$ extract as observed in Table 3. In P. falciparum assay, the concentrations necessary to inhibit the growth were lower in both cases, compared to $T$. gondii assay.

\section{Discussion and conclusions}

Grape-related industry has a big economic value worldwide, and there are several grape derived products like wine, which can be presented in many different formats depending on the grape type, elaboration process, etc. Due to the huge development of wine industry, a big amount of wine by-products is produced yearly. Finding a valuable use of these by-products will contribute to waste reduction adding a new source of economical profitability to the wine industry. At the same time, a more sustainable production process could report more benefits, due to the current trend in general society of developing environmentally friendly products; finding a use for a residue will influence positively the public opinion about wine industry which could also be returned in an increase of 
Table 1 Main polyphenols in white grape marc extracts

\begin{tabular}{llllll}
\hline Polyphenolic compound & Extract $\mathrm{HO}_{\mathrm{L}}(\mathrm{mg} / \mathrm{L})$ & Extract $\mathrm{HO}_{\mathrm{P}}(\mathrm{mg} / \mathrm{L})$ & Polyphenolic compound & ${\text { Extract } \mathrm{HO}_{\mathrm{L}}(\mathrm{mg} / \mathrm{L})}^{\text {Extract HO}_{\mathrm{P}}(\mathrm{mg} / \mathrm{L})}$ \\
\hline Catechin & 100.1 & 64.6 & Procyanidine (total) & 40.0 & 38.3 \\
Epicatechin & 54.9 & 38.3 & Procyanidine B2 & 8.2 & 10.4 \\
Epicatechin-gallate & 13.0 & 10.4 & Quercetin & 2.9 & 0.15 \\
Epigallocatechin-gallate & 0.31 & 0.15 & Isoquercetin & 63.5 & 7.3 \\
Gallic acid & 4.7 & 7.3 & Miquelianin & 44.7 & 64.6 \\
Cafeic acid & 0.007 & 0.02 & Rutin & 3.0 & 38.3 \\
Caftaric acid & - & 21.6 & Kaempferol & 4.0 & 10.4 \\
Phloroglucinic acid & 35.7 & 64.6 & & & \\
\hline
\end{tabular}

Concentration expressed in mg polyphenol/L extract (testing method: LC-MS/MS analysis)

consumption. As said, grape marc is one of the most abundant by-products of wine industry being in winemaking countries such as Spain around $1200 \mathrm{t}$ per year (Beres et al. 2017). Grape marc can also be considered a low-cost source of polyphenols, which could have interesting applications in many different industries (Guerra-Rivas et al. 2017; Mattos et al. 2017; González-Centeno et al. 2013) along with its upgrading to become a high valuable by-product (Yammine et al. 2018).

\section{Polyphenol-rich extracts}

In this work, the chemical composition and the anti-pathogenic effect of white grape marc extracts were evaluated. The polyphenolic composition of the $\mathrm{HO}_{\mathrm{L}}$ and $\mathrm{HO}_{\mathrm{P}}$ extracts was determined by LC-MS/MS, and the major components identified are listed in Table 1. Grape marc extract compositions vary depending on the method and solvent used for the extraction (Mendoza et al. 2013). Both extracts resulted to be very rich in polyphenols, and some differences were highlighted. One of the major differences is the content in phologlucinic acid, miquelianin, rutin, and kaempferol, which could have potential implications in their capacity as anti-microbiological agents.

\section{Activity against major infectious diseases}

Several studies demonstrate the activity of the different polyphenols purified as anti-bacterial (Arima et al.2002; Arima \& Danno 2002; Borges et al. 2013) and anti-parasitic (Slavic et al. 2009; Budiman et al. 2014; Chauhan et al. 2018) agents. Recently, their potential as synergic agents and their interaction with drugs when used as anti-bacterial (Miklasińska et al. 2016) and anti-parasitic (Somsak et al. 2018) agents, as well as the increase of the activity of such polyphenols when they are used in a combined way, has been a topic of interest (Arima et al. 2003a; Somsak et al. 2018). All this together seems to indicate that natural extracts similar to the one studied in the present work, and obtained with the aim to conserve the synergistic activity of their specific polyphenolic content, are in fact an efficient and economically viable approximation for the treatment of bacterial- and parasitic-derived infectious diseases.

\section{Bacteria}

Grape marc and grape seed extract-based films have been reported to show activity against bacteria (Corrales et al.
Fig. 1 Representation of the main polyphenols in white grape marc extracts. Concentration expressed in $\mathrm{mg}$ polyphenol/L extract (testing method: LC-MS/MS analysis)

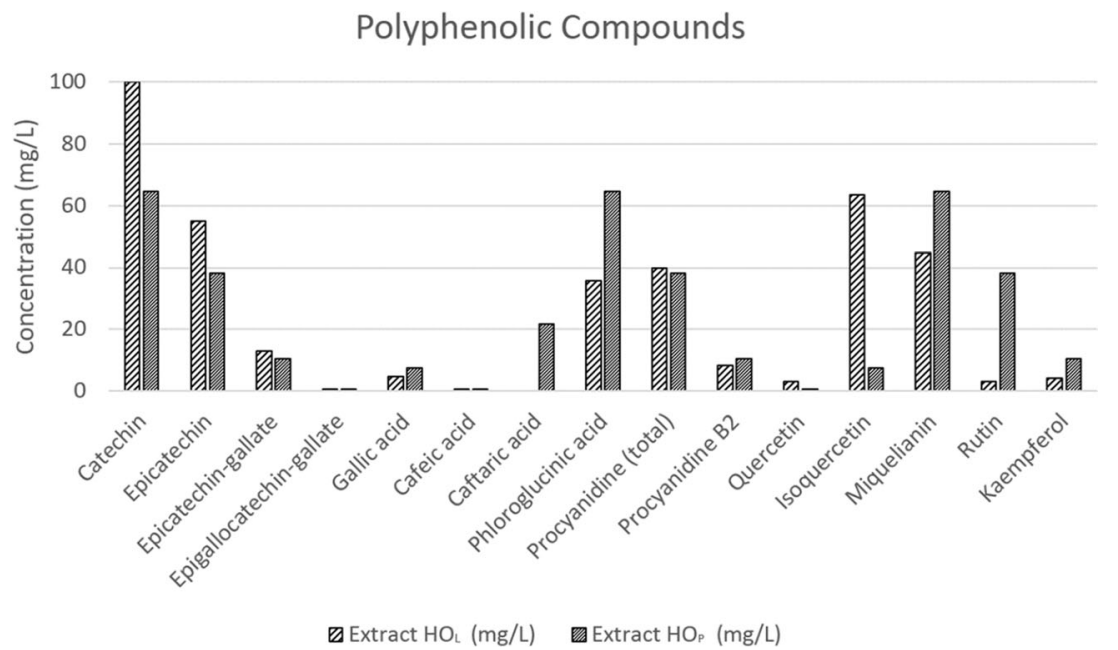


Table 2 Inhibitory concentration $50 \%\left(\mathrm{IC}_{50}\right)$ for anti-bacterial assays

\begin{tabular}{lll}
\hline Species & $\mathrm{IC}_{50}\left(\right.$ Extract $\left.\mathrm{HO}_{\mathrm{L}}\right)$ & $\mathrm{IC}_{50}\left(\mathrm{Extract}_{\mathrm{HO}}\right)$ \\
\hline Staphylococcus aureus & 0,809 & $<<0,625$ \\
Bacillus cereus & $<<0,625$ & $<<0,625$ \\
Escherichia coli & 0,718 & 0,795 \\
Streptococcus uberis & $<<0,625$ & 1349 \\
Salmonella enterica subsp. enterica & 0,752 & 1025 \\
\hline
\end{tabular}

Average values for triplicates were used to calculate $\mathrm{IC}_{50}$ concentrations using Quest Graph ${ }^{\mathrm{TM}} \mathrm{IC} 50$ Calculator. Concentration expressed in $\%(v / \mathrm{v})$

2009; Deng and Zhao 2011; Anastasiadi et al. 2009; Kajiya et al. 2004). In addition in previous studies, seed and skin extracts from grape winery by-products have been shown to have antibacterial and antifungal activity highlighting their potential to be used as anti-microbiological agents (Serra et al. 2008). Grape marc was found to be even richer in bioactive compounds than skin extracts, and its potential to treat food to prevent deterioration has already been emphasised (Sagdic et al. 2011a, 2011b; Tenore et al. 2011). Although many polyphenols are shared in both extracts, their total composition and concentration possess significant differences (Table 1), which may be related to their dissimilar behaviour in the antimicrobial tests performed.

\section{Parasites}

The effect of the two different extracts from grape marc collected in Galicia, Spain, on Apicomplexan and Oomycota parasites, T. gondii, P. falciparum, and P. cinnamomi, has been also investigated in this study.

Parasite resistance to current treatments has generated the necessity to find new drugs against different infectious diseases. Natural products appear as a promising source to find potential solutions and have been used in traditional medicine extensively (Adia et al. 2016; Borrmann et al. 2002; Kim et al. 2015; Ekanem and Brisibe 2010; El Babili et al. 2011). Among the natural products that have shown activities against different bacteria, fungi, and parasites, products obtained from grapes have been described to be involved in plant defence against pathogens as P. cinnamomi. Some of these products are phenolic compounds also active against human or animal pathogens, like Toxoplasma gondii (Azami et al. 2018), a parasite belonging to the phylum Apicomplexa causing the global foodborne disease toxoplasmosis. Apicomplexan diseases comprehend worldwide distribution infectious diseases such as toxoplasmosis or malaria.

As it can be observed in Fig. 2 and Table 3, anti-parasitic effect of the target objectives studied in the present work is clear. Specifically, activity against oomycete $P$. cinnamomi is observable for both extracts, being higher for $\mathrm{HO}_{\mathrm{L}}$. In fact, other extracts from natural origin and similar to the ones described in this study have shown activity against this species (Francisco et al. 2015). Differences in anti-parasitic capacity against $P$. cinnamomi between both extracts can be due to the different polyphenol concentrations they possess. Catechin and epicatechin concentrations are higher in $\mathrm{OH}_{\mathrm{L}}$. Catechin demonstrated their antifungal capacities against Oomycota (Veluri et al. 2004). Likewise, high levels of epicatechins increase plant resistance to P. cinnamomi infections (GarcíaPineda et al. 2010).

On the other hand, the $\mathrm{HO}_{\mathrm{P}}$ extract was the most active against $T$. gondii and $P$. falciparum, and the anti-parasitic activity of the extract increased in a concentration and timedependent manner. Since both of the extracts reduced the parasite load, we can suggest at this point that their activity is related to their polyphenol content. Other natural polyphenols have shown activity against $T$. gondii in the previous studies (Ietta et al. 2017; Moon and Sim 2008).

There are significant differences between both extracts in the concentrations of some particular polyphenols, like rutin and kaempferol, being higher in the $\mathrm{HO}_{\mathrm{P}}$, which is the more efficient one. For this reason, we could infer a potential action of these
Fig. 2 Inhibitory concentration $50 \%\left(\mathrm{IC}_{50}\right)$ for P. cinnamomi. Illustrative results of the experiment, 1 , control $(0 \%) ; 2$, extract $\mathrm{HO}_{\mathrm{L}} 4 \% ; 3$, extract $\mathrm{HO}_{\mathrm{L}}$ $10 \%$; 4, extract $\mathrm{HO}_{\mathrm{P}} 4 \% ; 5$, extract $\mathrm{HO}_{\mathrm{P}} 10 \%$. Concentration expressed in $\%(v / \mathrm{v})$

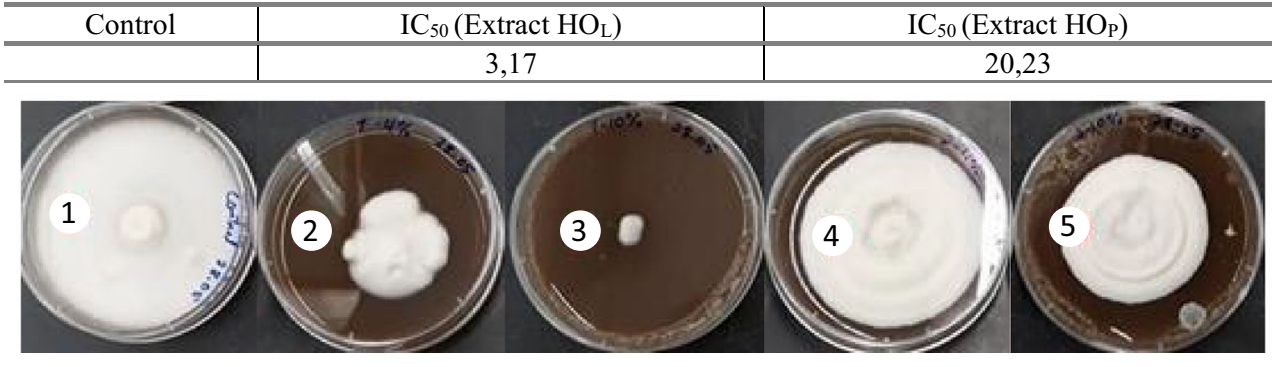

Average values for triplicates were used to calculate $\mathrm{IC}_{50}$ concentrations using Quest $\mathrm{Graph}^{\mathrm{TM}}$ IC50 Calculator 
Table 3 Inhibitory concentration $50 \%\left(\mathrm{IC}_{50}\right)$ for $T$. gondii and P. falciparum

\begin{tabular}{lll}
\hline Species & $\mathrm{IC}_{50}\left(\right.$ Extract $\left._{\mathrm{HO}}\right)$ & $\mathrm{IC}_{50}\left(\right.$ Extract $\left.\mathrm{HO}_{\mathrm{P}}\right)$ \\
\hline Toxoplasma gondii & 1,23 & 0,57 \\
Plasmodium falciparum & 1,07 & 0,26 \\
\hline
\end{tabular}

Average values for triplicates were used to calculate $\mathrm{IC}_{50}$ concentrations using Quest Graph ${ }^{\mathrm{TM}}$ IC50 Calculator. Concentration expressed in \% ( $/$ v)

specific polyphenols which have already been described as antimalarial agent in different studies (Julianti et al. 2014; Ganesh et al. 2012; Silveira et al. 2009; Somsak et al. 2018).

In other cases, natural polyphenols were used to complement activities of other anti-parasitic treatments as it is the case for resveratrol combined to sulfamethoxazoletrimethoprim against $T$. gondii (Bottari et al. 2015). AntiPlasmodium activity has also been tested several times by using polyphenols (Khasanah et al. 2017; Dohutia et al. 2017; Grellier et al. 2008). Our results demonstrate, for the first time, that both extracts of white grape marc reduce $T$. gondii infection in HFFs and that $P$. falciparum growth is also severely affected. Grape marc hydroalcoholic immunomodulatory and anti-inflammatory extracts were described to stimulate humoral immune responses in vaccine design for different parasitoses (Chiva-Blanch et al. 2012); this topic could be of potential interest for further research with white grape marc extracts in the future.

In summary, this is the first time that the same wine natural extract has been shown to be effective against both bacteria and parasites that attack humans, animals and plants; and this fact is confirmed for the two formulations obtained from white grape marc. Both extracts showed high antimicrobial potential, being effective for several kinds of bacteria and parasites belonging to different clades, all of them of economical and global health importance. In addition, the extracts assessed present a marked anti-pathogenical activity.

Accordingly, these results open up promising ways to valorise white grape marc, a by-product of wineries activity, due to the potential application of the target extracts as preservatives in cosmetic and food industry, sanitizing agents and phytosanitary products. In addition, it allows us to dream of a plant phenolic-based therapy against very concerning human diseases. Both extracts were obtained with solvents that are generally regarded as safe (GRAS).

In this way, anti-pathogenic activity and chemical composition assessed by LC-MS/MS indicate the high potential of the polyphenols from grape marc to act as possible antipathogenicals with large scope of action, which could lead this work to further studies concerning the development of therapeutic products of natural origin, targeted to the treatment of relevant infectious diseases.
Acknowledgements This research was supported by projects GPC2017/ 04 (Consolidated Research Groups Program) \& ED431E 2018/01 CrossResearch in Environmental Technologies (CRETUS) (Xunta de Galicia, Spain).

\section{References}

AAT Bioquest I (2019) Quest graph ${ }^{\mathrm{TM}}$ IC50 calculator

Adia MM, Emami SN, Byamukama R, Faye I, Borg-Karlson AK (2016) Antiplasmodial activity and phytochemical analysis of extracts from selected Ugandan medicinal plants. J Ethnopharmacol 186:14-19. https://doi.org/10.1016/J.JEP.2016.03.047

Álvarez-Casas M, García-Jares C, Llompart M, Lores M (2014) Effect of experimental parameters in the pressurized solvent extraction of polyphenolic compounds from white grape marc. Food Chem 157: 524-532. https://doi.org/10.1016/j.foodchem.2014.02.078

Anastasiadi M, Chorianopoulos NG, Nychas GJE, Karoutounian SA (2009) Antilisterial activities of polyphenol-rich extracts of grapes and vinification byproducts. J Agric Food Chem 57:457-463. https://doi.org/10.1021/jf8024979

Arima H, Ashida H, Danno G (2002) Rutin-enhanced antibacterial activities of flavonoids against Bacillus cereus and Salmonella enteritidis. Biosci Biotechnol Biochem 66:1009-1014. https://doi.org/10.1271/ bbb.66.1009

Arima H, Danno G (2002) Isolation of antimicrobial compounds from guava (Psidium guajava L.) and their structural elucidation. Biosci Biotechnol Biochem 66:1727-1730. https://doi.org/10.1271/bbb. 66.1727

Azami SJ, Amani A, Keshavarz H, Najafi-Taher R, Mohebali M, Faramarzi MA, Mahmoudi M, Shojaee S (2018) Nanoemulsion of atovaquone as a promising approach for treatment of acute and chronic toxoplasmosis. Eur J Pharm Sci 117:138-146. https://doi. org/10.1016/j.ejps.2018.02.018

El Babili F, Bouajila J, Souchard JP et al (2011) Oregano: chemical analysis and evaluation of its antimalarial, antioxidant, and cytotoxic activities. J Food Sci 76:512-518. https://doi.org/10.1111/j.17503841.2011.02109.x

Bargiacchi E, Campo M, Romani A et al (2017) Hydrolysable tannins from sweet chestnut (Castanea sativa Mill.) to improve tobacco and food/feed quality. Note 1: fraction characterization, and tobacco biostimulant effect for gall-nematode resistance. AIMS Agric Food 2:324-338. https://doi.org/10.3934/agrfood.2017.3.324

Benabderrahmane W, Amrani A, Benaissa O et al (2018) Chemical constituents, in vitro antioxidant and antimicrobial properties of ethyl acetate extract obtained from Cytisus triflorus l'Her. Nat Prod Res 22:1-5. https://doi.org/10.1080/14786419.2018.1519816

Benabderrahmane W, Lores M, Benaissa O et al (2019) Polyphenolic content and bioactivities of Crataegus oxyacantha L (Rosaceae). Nat Prod Res 5:1-6. https://doi.org/10.1080/14786419.2019. 1582044

Beres C, Costa GNS, Cabezudo I, da Silva-James NK, Teles ASC, Cruz APG, Mellinger-Silva C, Tonon RV, Cabral LMC, Freitas SP (2017) Towards integral utilization of grape pomace from winemaking process: a review. Waste Manag 68:581-594. https://doi.org/10.1016/J. WASMAN.2017.07.017

Borges A, Ferreira C, Saavedra MJ, Simões M (2013) Antibacterial activity and mode of action of ferulic and gallic acids against pathogenic Bacteria. Microb Drug Resist 19:256-265. https://doi.org/10. 1089/mdr.2012.0244

Borrmann S, Szlezák N, Faucher J et al (2002) Artesunate and praziquantel for the treatment of Schistosoma haematobium infections: a double-blind, randomized, placebo-controlled study. J Infect Dis 184:1363-1366. https://doi.org/10.1086/324004 
Bottari NB, Baldissera MD, Tonin AA, Rech VC, Nishihira VS, Thomé GR, Camillo G, Vogel FF, Duarte MM, Schetinger MR, Morsch VM, Tochetto C, Fighera R, da Silva AS (2015) Effects of sulfamethoxazole-trimethoprim associated to resveratrol on its free form and complexed with 2-hydroxypropyl- $\beta$-cyclodextrin on cytokines levels of mice infected by toxoplasma gondii. Microb Pathog 87:40-44. https://doi.org/10.1016/j.micpath.2015.07.013

Budiman I, Tjokropranoto R, Widowati W et al (2014) Antioxidant and anti-malarial properties of catechins. Br J Med Med Res 5:895-902. https://doi.org/10.9734/bjmmr/2015/11451

Chauhan K, Kaur G, Kaur S (2018) Activity of rutin, a potent flavonoid against SSG-sensitive and -resistant Leishmania donovani parasites in experimental leishmaniasis. Int Immunopharmacol 64:372-385. https://doi.org/10.1016/J.INTIMP.2018.09.026

Chiva-Blanch G, Urpi-Sarda M, Llorach R, Rotches-Ribalta M, Guillén M, Casas R, Arranz S, Valderas-Martinez P, Portoles O, Corella D, Tinahones F, Lamuela-Raventos RM, Andres-Lacueva C, Estruch R (2012) Differential effects of polyphenols and alcohol of red wine on the expression of adhesion molecules and inflammatory cytokines related to atherosclerosis: a randomized clinical trial. Am J Clin Nutr 95:326-334. https://doi.org/10.3945/ajcn.111.022889

Corrales M, Han JH, Tauscher B (2009) Antimicrobial properties of grape seed extracts and their effectiveness after incorporation into pea starch films. Int J Food Sci Technol 44:425-433. https://doi.org/ 10.1111/j.1365-2621.2008.01790.x

Davison EM (2002) Book Review. Plant Pathol 51:255-255. https://doi. org/10.1046/j.0032-0862.2002.00668_6.x

de O Ribeiro IC, Mariano EGA, Careli RT, Morais-Costa F, de Sant'Anna FM, Pinto MS, de Souza MR, Duarte ER (2018) Plants of the Cerrado with antimicrobial effects against Staphylococcus spp. and Escherichia coli from cattle. BMC Vet Res 14:32. https://doi. org/10.1186/s12917-018-1351-1

Deng Q, Zhao Y (2011) Physicochemical, nutritional, and antimicrobial properties of wine grape (cv. Merlot) pomace extract-based films. J Food Sci 76:309-317. https://doi.org/10.1111/j.1750-3841.2011. 02090.x

Dohutia C, Chetia D, Gogoi K, Sarma K (2017) Design, in silico and in vitro evaluation of curcumin analogues against Plasmodium falciparum. Exp Parasitol 175:51-58. https://doi.org/10.1016/j. exppara.2017.02.006

Ekanem AP, Brisibe EA (2010) Effects of ethanol extract of Artemisia annua L. against monogenean parasites of Heterobranchus longifilis. Parasitol Res 106:1135-1139. https://doi.org/10.1007/s00436-010$1787-0$

European Centre for Disease Prevention and Control (ECDC), European Food Safety Authority, European Medicines Agency (2017) Second joint interagency antimicrobial consumption and resistance analysis (JIACRA) report. John Wiley \& Sons, Ltd

European Food Safety Authority (EFSA) (2019) Monitoring and analysis of food-borne diseases. http://www.efsa.europa.eu/en/topics/topic/ monitoring-foodborne-diseases. Accessed 29 Apr 2019

Castillo-Reyes F, Hernandez-Castillo FD, Clemente-Constantino JA et al (2015) In vitro antifungal activity of polyphenols-rich plant extracts against Phytophthora cinnamomi Rands. African J Agric Res 10: 4554 4560. https://doi.org/10.5897/ajar2013.8072

Friedman M (2014) Antibacterial, antiviral, and antifungal properties of wines and winery byproducts in relation to their flavonoid content. J Agric Food Chem 62:6025-6042. https://doi.org/10.1021/ jf501266s

Ganesh D, Fuehrer HP, Starzengrüber P, Swoboda P, Khan WA, Reismann JA, Mueller MS, Chiba P, Noedl H (2012) Antiplasmodial activity of flavonol quercetin and its analogues in Plasmodium falciparum: evidence from clinical isolates in Bangladesh and standardized parasite clones. Parasitol Res 110: 2289-2295. https://doi.org/10.1007/s00436-011-2763-z
García-Pineda E, Benezer-Benezer M, Gutiérrez-Segundo A, RangelSánchez G, Arreola-Cortés A, Castro-Mercado E (2010) Regulation of defence responses in avocado roots infected with Phytophthora cinnamomi (Rands). Plant Soil 331:45-56. https:// doi.org/10.1007/s11104-009-0225-5

González-Centeno MR, Jourdes M, Femenia A, Simal S, Rosselló C, Teissedre PL (2013) Characterization of polyphenols and antioxidant potential of white grape pomace byproducts (Vitis vinifera L.). J Agric Food Chem 61:11579-11587. https://doi.org/10.1021/ jf403168k

Grellier P, Nemeikaite-Čeniene A, Šarlauskas J, Čenas N (2008) Role of single-electron oxidation potential and lipophilicity in the antiplasmodial in vitro activity of polyphenols: comparison to mammalian cells. Zeitschrift fur Naturforsch - Sect C J Biosci 63:445450. https://doi.org/10.1515/znc-2008-5-622

Guerra-Rivas C, Gallardo B, Mantecón ÁR, del Álamo-Sanza M, Manso $\mathrm{T}$ (2017) Evaluation of grape pomace from red wine by-product as feed for sheep. J Sci Food Agric 97:1885-1893. https://doi.org/10. 1002/jsfa.7991

Gutteridge JMC, Halliwell B (2010) Antioxidants: molecules, medicines, and myths. Biochem Biophys Res Commun 393:561-564. https:// doi.org/10.1016/J.BBRC.2010.02.071

Ietta F, Maioli E, Daveri E, Gonzaga Oliveira J, da Silva RJ, Romagnoli R, Cresti L, Maria Avanzati A, Paulesu L, Barbosa BF, Gomes AO, Roberto Mineo J, Ferro EAV (2017) Rottlerin-mediated inhibition of toxoplasma gondii growth in BeWo trophoblast-like cells. Sci Rep 7:1279. https://doi.org/10.1038/s41598-017-01525-6

Judelson HS, Blanco FA (2005) The spores of Phytophthora: weapons of the plant destroyer. Nat Rev Microbiol 3:47-58

Julianti T, De Mieri M, Zimmermann S et al (2014) HPLC-based activity profiling for antiplasmodial compounds in the traditional Indonesian medicinal plant Carica papaya L. J Ethnopharmacol 155:426-434. https://doi.org/10.1016/j.jep.2014.05.050

Kajiya K, Hojo H, Suzuki M, Nanjo F, Kumazawa S, Nakayama T (2004) Relationship between antibacterial activity of (+)-catechin derivatives and their interaction with a model membrane. J Agric Food Chem 52:1514-1519. https://doi.org/10.1021/jf0350111

Khasanah U, WidyaWaruyanti A, Hafid A, Tanjung M (2017) Antiplasmodial activity of isolated polyphenols from Alectryon serratus leaves against 3D7 Plasmodium falciparum. Pharm Res 9: 57. https://doi.org/10.4103/pr.pr_39_17

Kim WS, Choi WJ, Lee S, Kim WJ, Lee DC, Sohn UD, Shin HS, Kim W (2015) Anti-inflammatory, antioxidant and antimicrobial effects of artemisinin extracts from Artemisia annua L. Korean J Physiol Pharmacol 19:21-27. https://doi.org/10.4196/kjpp.2015.19.1.21

Lores M, García-Jares C, Álvarez-Casas M, Llompart M (2014a) Extracto polifenólico a partir de residuos de uva blanca. ES 2443 547

Lores M,García-Jares C, Álvarez-Casas M, Llompart M (2014b) Polyphenolic extract from white grape residue. WO 2014/013122 A1

Mattos GN, Tonon RV, Furtado AAL, Cabral LM (2017) Grape byproduct extracts against microbial proliferation and lipid oxidation: a review. J Sci Food Agric 97:1055-1064

Mendoza L, Cotoras M, Vivanco M et al (2013) Evaluation of antifungal properties against the phytopathogenic fungus botrytis cinerea of anthocyanin rich-extracts obtained from grape pomaces. J Chil Chem Soc 58:1725-1727. https://doi.org/10.4067/S071797072013000200018

Miklasińska M, K pa M, Wojtyczka RD et al (2016) Catechin hydrate augments the antibacterial action of selected antibiotics against Staphylococcus aureus clinical strains. Molecules 21:244. https:// doi.org/10.3390/molecules 21020244

Moon HI, Sim J (2008) Antimalarial activity in mice of resveratrol derivative from Pleuropterus ciliinervis. Ann Trop Med Parasitol 102: 447-450. https://doi.org/10.1179/136485908x300832 
Murphy D, Ricci A, Auce Z et al (2017) EMA and EFSA joint scientific opinion on measures to reduce the need to use antimicrobial agents in animal husbandry in the European Union, and the resulting impacts on food safety (RONAFA). EFSA J 15. https://doi.org/10. 2903/j.efsa.2017.4666

Piscopo M, Tenore GC, Notariale R, Maresca V, Maisto M, de Ruberto F, Heydari M, Sorbo S, Basile A (2019) Antimicrobial and antioxidant activity of proteins from Feijoa sellowiana berg. Fruit before and after in vitro gastrointestinal digestion. Nat Prod Res 2019(2):1-5. https://doi.org/10.1080/14786419.2018.1543686

Placha I, Chrastinova L, Laukova A, Cobanova K, Takacova J, Strompfova V, Chrenkova M, Formelova Z, Faix S (2013) Effect of thyme oil on small intestine integrity and antioxidant status, phagocytic activity and gastrointestinal microbiota in rabbits. Acta Vet Hung 61:197-208. https://doi.org/10.1556/AVet.2013.012

Sagdic O, Ozturk I, Ozkan G, Yetim H, Ekici L, Yilmaz MT (2011a) RPHPLC-DAD analysis of phenolic compounds in pomace extracts from five grape cultivars: evaluation of their antioxidant, antiradical and antifungal activities in orange and apple juices. Food Chem 126: 1749-1758. https://doi.org/10.1016/j.foodchem.2010.12.075

Sagdic O, Ozturk I, Yilmaz MT, Yetim H (2011b) Effect of grape pomace extracts obtained from different grape varieties on microbial quality of beef Patty. J Food Sci 76:M515-M521. https://doi.org/10.1111/j. 1750-3841.2011.02323.x

Seeber F, Steinfelder S (2016) Recent advances in understanding apicomplexan parasites. F1000Research 5:1369. https://doi.org/10. 12688/f1000research.7924.1

Serra AT, Matias AA, Nunes AVM et al (2008) In vitro evaluation of olive- and grape-based natural extracts as potential preservatives for food. Innov Food Sci Emerg Technol 9:311-319. https://doi. org/10.1016/j.ifset.2007.07.011

Silveira P, Vashist U, Cabral A, Amaral KB, Soares GL, Dagosto M (2009) Effect of rutin and chloroquine on white Leghorn chickens infected with Plasmodium (Bennettinia) juxtanucleare. Trop Anim Health Prod 41:1319-1323. https://doi.org/10.1007/s11250-0099317-8

Simões M, Bennett RN, Rosa EAS (2009) Understanding antimicrobial activities of phytochemicals against multidrug resistant bacteria and biofilms. Nat Prod Rep 26:746-757

Slavic K, Derbyshire ET, Naftalin RJ, Krishna S, Staines HM (2009) Comparison of effects of green tea catechins on apicomplexan hexose transporters and mammalian orthologues. Mol Biochem Parasitol 168:113-116. https://doi.org/10.1016/j.molbiopara.2009. 06.008

Smilkstein M, Sriwilaijaroen N, Kelly JX, Wilairat P, Riscoe M (2004) Simple and inexpensive fluorescence-based technique for highthroughput antimalarial drug screening. Antimicrob Agents Chemother 48:1803-1806. https://doi.org/10.1128/AAC.48.5. 1803-1806.2004
Somsak V, Damkaew A, Onrak P (2018) Antimalarial activity of Kaempferol and its combination with Chloroquine in Plasmodium berghei infection in mice. J Pathog 2018:1-7. https://doi.org/10. 1155/2018/3912090

Tauxe RV, Doyle MP, Kuchenmüller T, Schlundt J, Stein CE (2010) Evolving public health approaches to the global challenge of foodborne infections. Int J Food Microbiol 139:S16-S28. https:// doi.org/10.1016/j.ijfoodmicro.2009.10.014

Tayengwa T, Mapiye C (2018) Citrus and winery wastes: promising dietary supplements for sustainable ruminant animal nutrition, health, production, and meat quality. Sustain. 10:3718

Taylor RL (1950) American association for the advancement of science. J Clin Endocrinol Metab 10:1361-1362. https://doi.org/10.1210/ jcem-10-10-1361

Tenore GC, Basile A, Novellino E (2011) Antioxidant and antimicrobial properties of polyphenolic fractions from selected Moroccan red wines. J Food Sci 76:C1342-C1348. https://doi.org/10.1111/j. 1750-3841.2011.02426.x

Tortora F, Notariale R, Maresca V, Good KV, Sorbo S, Basile A, Manna C (2019) Phenol-rich Feijoa sellowiana (pineapple guava) extracts protect human red blood cells from mercury-induced cellular toxicity. Antioxidants 8:220. https://doi.org/10.3390/antiox8070220

Veluri R, Weir TL, Bais HP, Stermitz FR, Vivanco JM (2004) Phytotoxic and antimicrobial activities of catechin derivatives. J Agric Food Chem 52:1077-1082. https://doi.org/10.1021/jf030653+

World Health Organization Malaria (2019) In: Malaria. https://www. who.int/news-room/fact-sheets/detail/malaria . Accessed 29 Apr 2019

Yadav D, Kumar A, Kumar P, Mishra D (2015) Antimicrobial properties of black grape (Vitis vinifera L.) peel extracts against antibioticresistant pathogenic bacteria and toxin producing molds. Indian J Pharmacol 47:663. https://doi.org/10.4103/0253-7613.169591

Yammine S, Brianceau S, Manteau S, Turk M, Ghidossi R, Vorobiev E, Mietton-Peuchot M (2018) Extraction and purification of high added value compounds from by-products of the winemaking chain using alternative/nonconventional processes/technologies. Crit Rev Food Sci Nutr 58:1375-1390. https://doi.org/10.1080/10408398. 2016.1259982

Yan C, Liang LJ, Zheng KY, Zhu XQ (2016) Impact of environmental factors on the emergence, transmission and distribution of toxoplasma gondii. Parasites and Vectors 9:137

Zampelas A, Micha R (2015) Antioxidants in health and disease. BMJ Publishing Group

Publisher's note Springer Nature remains neutral with regard to jurisdictional claims in published maps and institutional affiliations. 